\title{
Der nahe und der ferne Blick
}

\section{Peter Marko}

Dr. med., Mitglied FMH

Der vorliegende Text wurde anlässlich einer Lesung der ASEM (Association Suisse des Ecrivains Médecins) in Affoltern am Albis am 27. Februar 2016 präsentiert.
Im Gesicht der vom Bad in Formalin ausgedörrten Leichen konnte man ihre persönlichen Züge gut erkennen. Sie warteten auf den Obduktionstischen auf unsere erste ärztliche Tätigkeit. Jedem von uns wurde ein Körperteil zugewiesen. Es brauchte eine ziemliche Überwindung, die unversehrten, wehrlosen Menschen mit dem Skalpell zu verletzen, den ersten Schnitt zu setzen. Bei der Präparation schielten wir dauernd in die anatomischen Atlanten, die neben den Leichen lagen, und achteten, dass wir sie mit unseren von Fett und anderen Geweben verschmutzten Gummihandschuhen nicht verschmierten. Je mehr wir in den Körper vordrangen, desto mehr fiel die Mischung von Scheu, Rücksicht und Ekel von uns ab, verschwanden unsere Hemmungen, und wir bekamen eine eigentümliche Beziehung zu "unserer» Leiche, die uns bereitwillig und reglos als Lehrmittel diente. Die Leichen glichen immer weniger einem Menschen, bestanden zuletzt nur noch aus Knochen, aber wir schätzten sie zunehmend. Ausser Anatomie lernten wir unbemerkt noch etwas Wichtiges - sich auf ein Gebiet, eine Aufgabe zu konzentrieren, den Blick und das Interesse ein- zuengen. Ein Arzt, in welchem Fach auch immer, braucht solche Fokussierungen, um seine Arbeit richtig gut zu verrichten. Die Kunst ist, sich von dieser nützlichen vorübergehenden Verengung wieder zu befreien und den Patienten in den verschiedenen Zusammenhängen als ganzen Menschen wahrzunehmen, zu berücksichtigen und zu betreuen. Ohne diese Fähigkeit ist man zwar ein guter Spezialist, aber kein guter Arzt. Gewohnte Umstände, die bieten, was man benötigt, um die Arbeit ungestört verrichten zu können, erleichtern die Fokussierung. Es gibt Ärzte, die ausserhalb der Praxis oder des Spitals nicht arbeiten können. Dagegen machen andere gerne Hausbesuche oder eilen zu Notfällen. Einmal in den Ferien in einem fremden Land, dessen Sprache ich nur sehr spärlich beherrschte, fuhren wir mit dem Linienbus. An einer Haltestelle stieg eine alte Frau mit einem langen schwarzen Rock ein. Sie wollte nicht absitzen. Bald sah man, dass sich auf dem Boden zwischen ihren Beinen eine Blutlache ausbreitete. Ich war ohne Notfalltasche unterwegs, die mir mit dem Blutdruckmesser Anlass zu einer einigermassen vernünftigen, gewohnten und vor allem mich

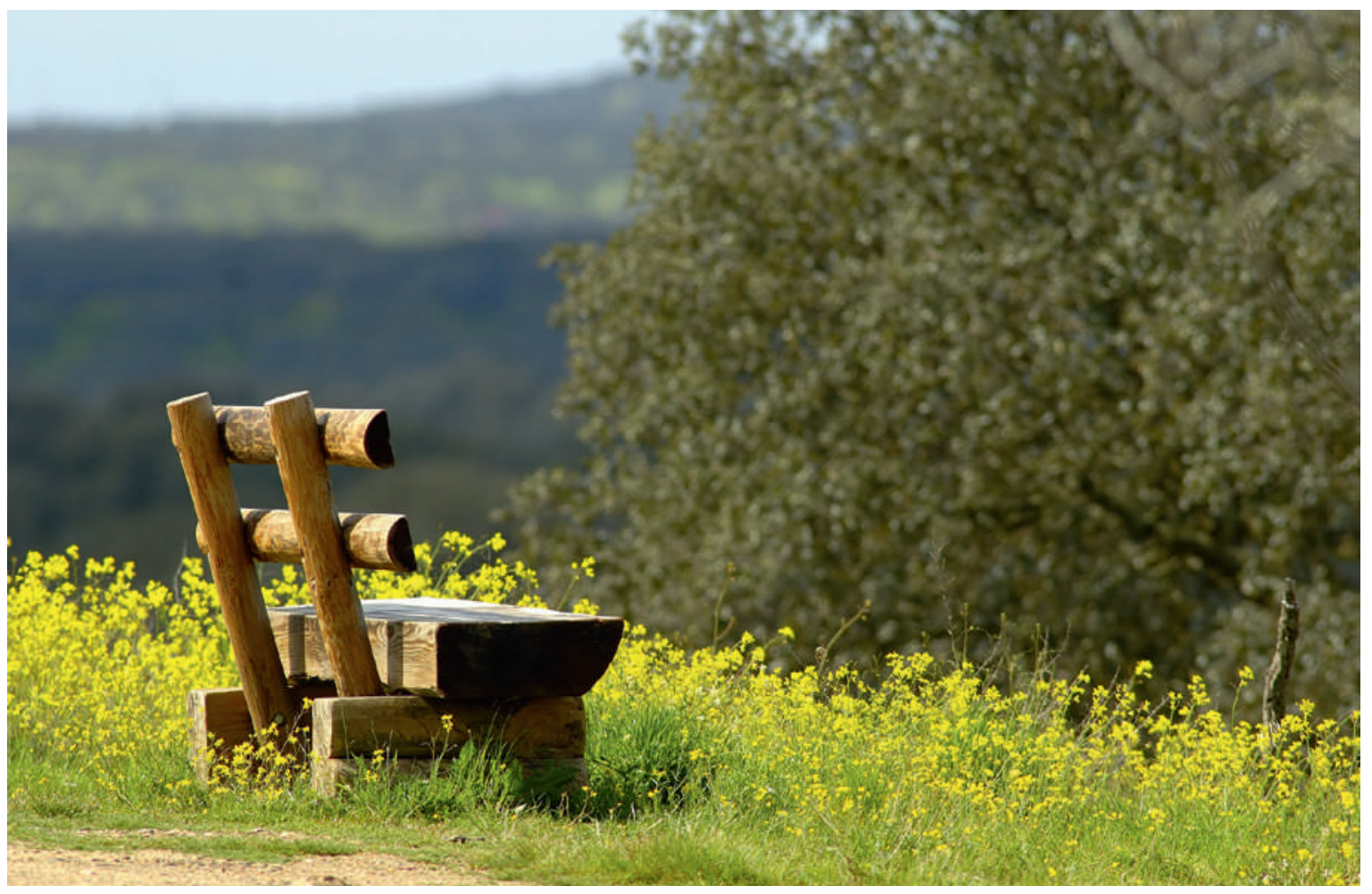


beruhigenden Tätigkeit bieten würde. Ich war im ganzen Bus vermutlich der Einzige, der eine Ahnung über die Gefährlichkeit der Lage hatte. Ich wurde blass, mir wurde schlecht, ich fiel fast in Ohnmacht. Der Bus hielt unbeirrt auf allen vorgesehenen Haltestellen, aber dann bog er doch von seiner Strecke mehr als hundert Meter ab zum Spital. Der Fahrer übergab die Frau dem Pflegepersonal, holte einen Kübel mit kaltem Wasser, wischte ruhig die Blutlache weg und kehrte wieder auf die vorgegebene Route zurück. Ich beruhigte und erholte mich auch. Meine Frau verstand meine Reaktion nach den vielen viel schlimmeren Notfallsituationen in Spitälern, der Praxis und den Notfalleinsätzen draussen nicht.

Kurz nachdem ich die Praxis aufgab, begann ich im freiwilligen Hospizdienst mitzuarbeiten. Ich verweile Stunden neben den schwerkranken, oft sterbenden Menschen. Am Anfang war es schwierig, daran zu denken, dass sie am Sterben sind. Besonders bei den jüngeren dachte ich auch, was, wenn es eigene Kinder wären. Nach dem ich in der Praxis Sterbende betreute und der Schwiegervater wie meine Mutter bei uns zu Hause starben, dachte ich, ich ertrage es leichter. Aber damals war ich eher kurz dabei, selten allein und abgelenkt von Gesprächen, Aufgaben und Überlegungen, was noch getan werden soll. Jetzt bin ich stundenlang alleine mit teilweise schwer leidenden, unruhigen, verwirrten Menschen und treffe nur einfache Entscheidungen, aber mit unmittelbaren Folgen. Mit der Zeit blende ich die Traurigkeit und die Schwere des Sterbens immer mehr aus. Nicht selten denke ich, der Tod solle sich beeilen und das Leiden beenden. Ich bemühe mich, den Patienten die Gegenwart so angenehm zu gestalten, wie es nur geht, unabhängig davon, was sie erwartet. Wenn sie es möchten, lese ich Kurzgeschichten vor. Ich versuche den Lesestoff der Person und ihrer Vergangenheit, ihren Interessen und ihrem Beruf anzupassen. Manchmal haben wir es zusammen sogar lustig, eine Erfahrung, die ich auch von anderen «Hospizlern» höre.

$\mathrm{Ab}$ und zu liest man, dass Leute auch im hohen Alter unerwartet sterben. Diese Ansicht kann ich, als ein ehemaliger Pfadfinder, der die Parole «Sei bereit!» verinnerlichte, nicht teilen. Nebst anderem habe ich mir lange Zeit den Kopf zerbrochen mit den Gedanken, wie meine Urne aussehen und wo sie aufbewahrt werden soll. Schliesslich vermachte ich meine Leiche dem Anatomischen Institut. Meine Frau folgt mir in dieser Entscheidung. Wir vereinfachen unseren Verbliebenen, die damit einverstanden sind (was bleibt ihnen übrig?), das Leben. Ein Anruf (so bald wie möglich nach unserem Tod) reicht, und man kommt uns holen. Die Form der Urne ist einheitlich, und sie wird, falls wir es wünschen, auf dem Gebiet des Friedhofs, das für die Universität reserviert ist, aufbewahrt. Kein schlechter Platz nach einer mehrjährigen akademischen Karriere auf drei Almae Matres. Als einen unermüdlichen, oft lästigen Möchtegernpädagogen und Weltverbesserer freut mich die Aussicht, dass die Studenten dazu an mir auch noch zu fokussieren lernen werden. Auf eine Weise wird es der Gipfel und das Ende meiner Eitelkeit. Mit diesem Schritt trennt also der Tod unsere Ehe nicht.

Bildnachweis

(c) Ekaterina Garyuk | Dreamstime.com 